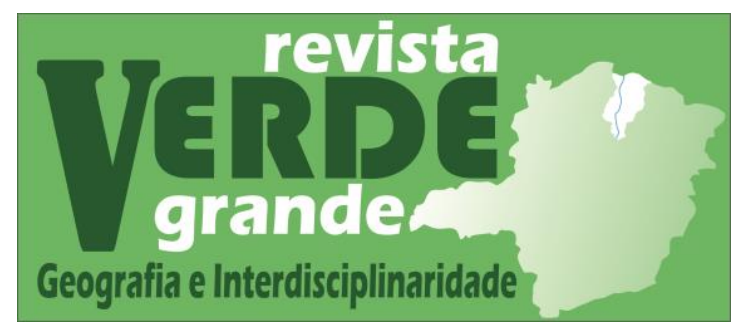

\title{
PAULO RIBEIRO: UM CAVALEIRO DA UTOPIA
}

\author{
Laura Murta ${ }^{1}$ https://orcid.org/0000-0002-0463-505X
}

${ }^{1}$ Bacharel em Comunicação - Universidade de Brasília. Assessoria de imprensa. E-mail: $\underline{\text { lauramurta2@gmail.com }}$

Paulo Ribeiro, foi sociólogo, foi Secretário Municipal de Meio Ambiente e Desenvolvimento Sustentável, cargo que ocupou entre os anos de 2005 a 2008 em seu primeiro mandato e depois entre os anos de 2017 e 2021, quando faleceu; Foi presidente da Fundação Darcy Ribeiro, no período de 2008 e 2016 e manteve-se membro do Conselho Curador da instituição desde a sua criação, em 1997 até o fim da sua vida. Foi assessor do político e escritor Darcy Ribeiro na Secretaria Extraordinária de Ciência e Cultura do Estado do Rio de Janeiro; Na Secretaria de Estado de Desenvolvimento Social de Minas Gerais e no Senado Federal. Presidiu: A Fundação Roquette Pinto, administradora da TVE Brasil e da Rádio MEC, vinculada à Secretaria Nacional de Comunicação da Presidência da República; A Rede Minas de Televisão; A Companhia de Habitação de Minas Gerais - Cohab.

Seria uma síntese sobre quem foi Paulo Ribeiro, mas pouco compatível com a realidade. Paulinho, como sempre foi chamado não era e nunca foi sintético. Abundante, inquieto, dado a rompantes, inteligente, irreverente, despudoradamente corajoso, Paulinho sempre foi um apaixonado pela vida, por sua cidade, por sua gente, sua história. Vocacionado para o fazer coletivo, um eterno menino do dedo verde!

Paulo de F. Ribeiro, sexto filho de Mário e Jacy Ribeiro. Sobrinho predileto de Darcy Ribeiro. Quando menino sonhava ser escoteiro ou papa. Na medida em que cresceu, cresceram os sonhos e Paulinho, ganhou novos rumos, ampliou os horizontes, saiu de Montes Claros, sem deixar que a cidade nunca saísse dele. Foi estudar ciências sociais na Universidade Federal Fluminense, viver o Rio de Janeiro no auge dos anos de 1980. Despudorado, livre, criativo, Paulinho cresceu cercado de privilégios, como bem o reconhecia, mas foi exatamente por isso 
que se impôs uma tarefa de fazer pelo o outro aquilo que a "a vida" se encarregará de fazer por ele.

Com a mãe, Dona Jacy, Paulinho dizia ter aprendido sobre a beleza e o bem-viver como um direito a ser legitimado para todos. Mãe jardineira, poetisa, apaixonada pelo sertão, por Montes Claros, por sua gente, Paulinho a "culpava" por tê-lo feito crescer com esse sentimento, essa obrigação.

No emaranhado de gentes que formaram o homem Paulo Ribeiro é que se percebe a sua habilidade em fazer caber nos seus passos, passos de tantos outros. Do pai, Mário Ribeiro, admirava a genuína astúcia de um ser político. Um político amoroso, acessível, Marão, como é imortalizado em Montes Claros. Do tio Darcy Ribeiro, tornou-se um discípulo, herdou a audácia, a capacidade de sonhar grande, para realizar grande também. Paulinho gostava de gente, e de gente com boas ideias, a ponto de incorpora-las e concretizá-las. Conhecedor dos estudos de Simeão Ribeiro, um grande pesquisador e defensor das nossas riquezas, Paulinho passou a sonhar e lutar pela criação do Parque Estadual da Lapa Grande. Com o avô Pacífico, aprendeu ainda menino que gente sem verde não segue em frente. Foi ouvinte e aprendiz de Ivo das Chagas, José Gonçalves Ulhôa, Célio Valle, Apolo Lisboa, ouviu Irineus, Tonhos, Necretos, Josés, Geraldos, Marias, Aritana, vida a fora.

Como secretário Municipal de Meio Ambiente e Desenvolvimento Sustentável, pasta que ajudou a implementar no período de 2005 a 2007, procurou construir de forma regimental políticas públicas permanentes e irreversíveis para a conservação de áreas verdes no município e a consolidação do processo de educação ambiental. Em sua primeira gestão como secretário municipal, criou um amplo programa de arborização urbana, com o plantio e a distribuição de mudas em toda a cidade, contribuindo para uma Montes Claros mais bonita, mais arborizada, colorida e com muito mais verde em todos os bairros, praças e jardins. Paulinho tinha orgulho de ser autor da Lei Municipal do Ecocrédito ${ }^{1}$, primeira lei brasileira que previa o pagamento aos produtores rurais pela preservação ambiental, sobretudo, em áreas de recarga e nascentes. Primeira lei de proteção ambiental que estabelece com o pequeno produtor rural uma relação de parceria e corresponsabilidades, Paulinho tinha paixão pelo nosso pioneirismo!

Outro filhote que o orgulhava era o Vale Verde, uma espécie de passe-livre, com a gratuidade do transporte coletivo aos fins de semana e feriados para áreas verdes da cidade, especialmente os parques municipais. Ele também coordenou o processo de criação do Parque Estadual da Lapa Grande, com o objetivo de proteger os mananciais e grutas, além do sítio

\footnotetext{
${ }^{1}$ Disponível em: http://www.montesclaros.mg.gov.br/Meio\%20Ambiente/legisla/Lei\%203.545-2006.pdf. Acesso em: ago. 2021.
} 
arqueológico presente na Unidade de Conservação. Foi o idealizador da Expedição Caminhos dos Geraes, criada com a tarefa de avaliar a situação do patrimônio natural da região, catalogando espécies e avaliando possíveis danos ambientais decorrente do uso inadequado dos recursos naturais por empreendimentos como a silvicultura, a mineração e a produção de carvão na região. Além de produzir um inventário ambiental da região, a Expedição Caminhos dos Geraes tem mapeado os atrativos turísticos do Norte de Minas, rompendo com o estigma de que somos uma região pobre, desprovida de belezas e atrativos.

Paulinho foi Secretário Municipal de Comunicação e Articulação Institucional, inaugurando uma experiência de abertura do diálogo da Administração Municipal com a cidade e os seus diversos públicos.

Foi presidente do Diretório Estudantil de Montes Claros - DEMC, de 1979 a 1980. Tinha um orgulho danado por ter realizado na Praça da Catedral de Montes Claros, o primeiro grande Ato Público contra a ditadura militar da cidade.

Foi presidente da Fundação Darcy Ribeiro - FUNDAR, no período de 2008 e 2016 e permaneceu membro do seu Conselho Curador. Instituição cultural e educacional, de pesquisa e desenvolvimento científico, criada por Darcy Ribeiro, com o objetivo de manter vivos seu pensamento e ideias.

Enquanto esteve presidente da FUNDAR, Paulinho realizou o sonho derradeiro de Darcy. Pousar, numa espécie de oca voadora, uma mistura de casa xinguana e disco voador, o Memorial Darcy Ribeiro, o Beijódromo da UnB. Inaugurado por dois presidentes da república, Luís Inácio Lula da Silva e Pepe Mujica, à época presidente do Uruguai e ministros de estado, artistas e intelectuais. Junto com os índios que Darcy ajudou a salvar com a criação do Parque Indígena do Xingu, Paulinho celebrou o seu Kuarup. Publicou coleções, livros e tantos outros fazimentos.

Foi assessor de Darcy Ribeiro na Secretaria Extraordinária de Ciência e Cultura do Estado do Rio de Janeiro; Na Secretaria de Estado de Desenvolvimento Social de Minas Gerais e no Senado Federal. Presidiu: A Fundação Roquette Pinto, administradora da TVE Brasil e da Rádio MEC, vinculada à Secretaria Nacional de Comunicação da Presidência da República; A Rede Minas de Televisão; A Companhia de Habitação de Minas Gerais Cohab. Criou e implantou em Montes Claros a TV Geraes, emissora educativa e com forte produção local.

Nos últimos três anos, como Secretário Municipal de Meio Ambiente e Desenvolvimento Sustentável, criou os Parques - Sagarana, Canelas, Belvedere, Mangues e Jardim Olímpio; implantou o Onda Verde, programa que leva internet de graça para os 
parques e praças da cidade, e o Artes nas Praças, programa que vem impactando Montes Claros, com várias esculturas espalhadas pela cidade. Paulinho conseguia enxergar longe, soluções duradoras. Foi o articulador e mediador de uma experiência de ressocialização de apenados do sistema prisional, instituindo numa parceria entre a Prefeitura e o Ministério Público o projeto Muito além das prisões, uma oportunidade de formação de mão de obra e cidadania para homens e mulheres que cumprem medidas restritivas de liberdade.

Liberdade, palavra que expressa a natureza do Paulinho. Liberdade que era condição elementar para tudo o que ele fazia ou sonhava fazer.

Nascido numa cidade já centenária e numa família que desde sempre o fez reconhecer a singularidade de ser de Montes Claros. Paulinho acreditava que ser de Montes Claros o tornava diferente de tudo. Cresceu vendo potência em tudo o que era daqui. Cresceu com orgulho por ser daqui. E foi com esse sentimento, de orgulho e de gratidão, que pautou a sua caminhada, projetando o futuro, cuidando do presente e respeitando o seu passado e a lança apontada para a lua.

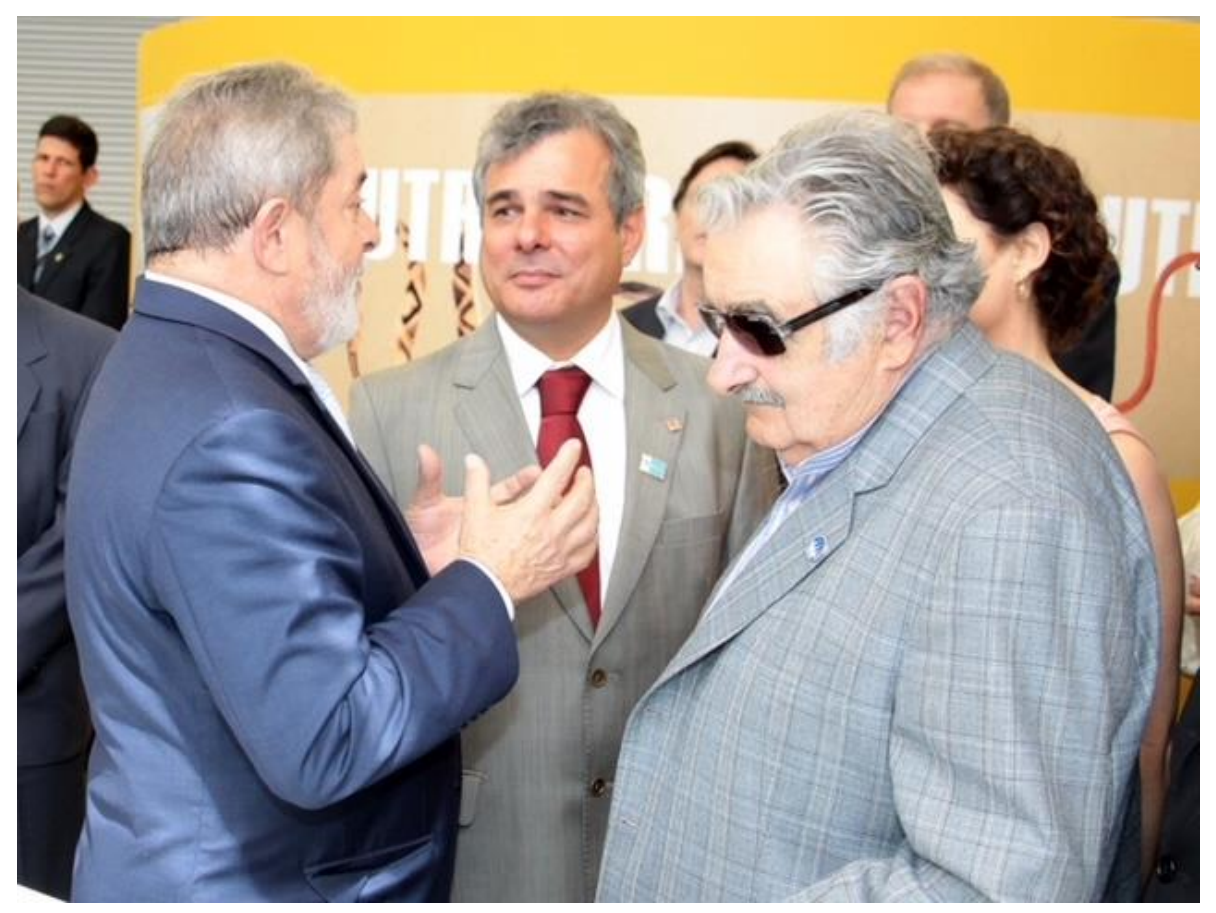

Fonte: Ricardo Brasil- Inauguração do Memorial Darcy Ribeiro- Brasília, dezembro de 2010. 


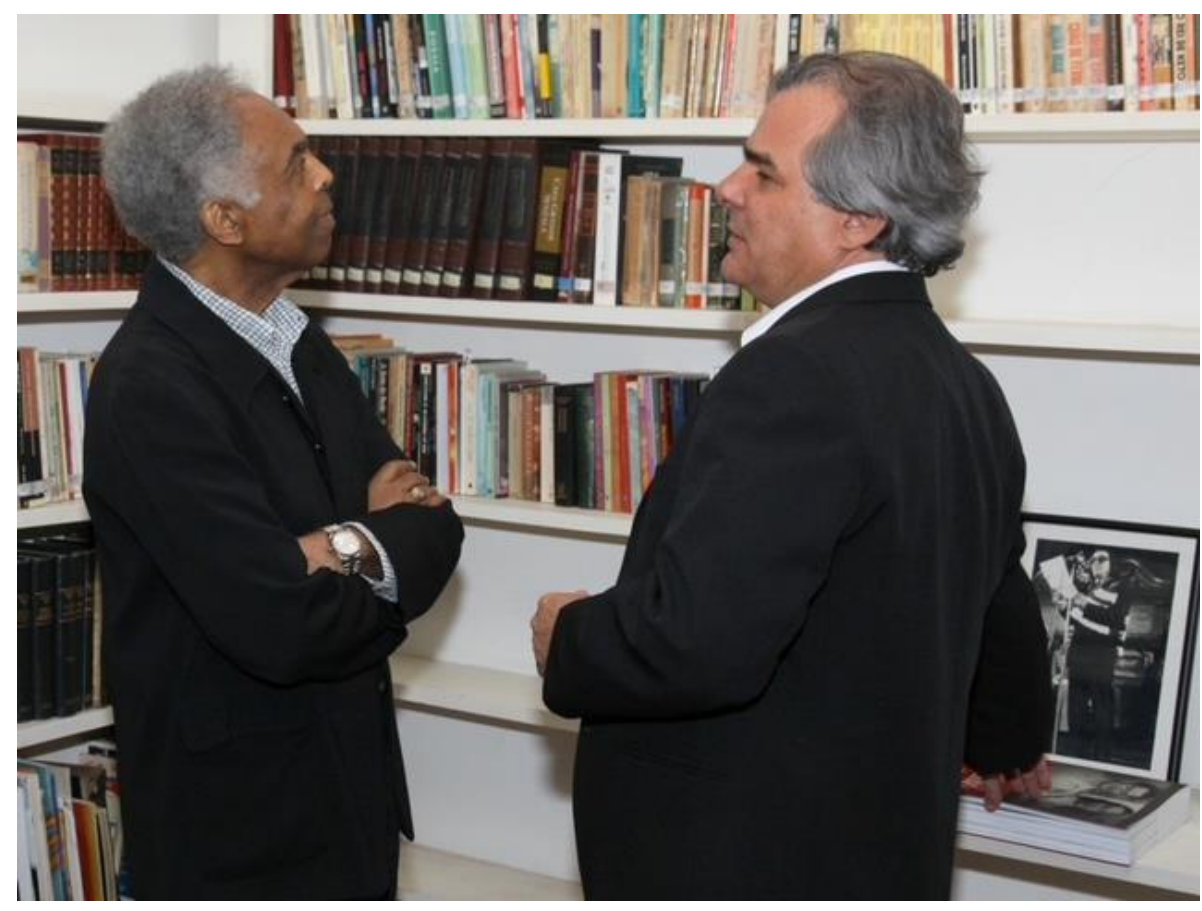

Fonte: Ricardo Brasil- Prêmio Darcy Ribeiro - Rio de Janeiro, outubro de 2014.

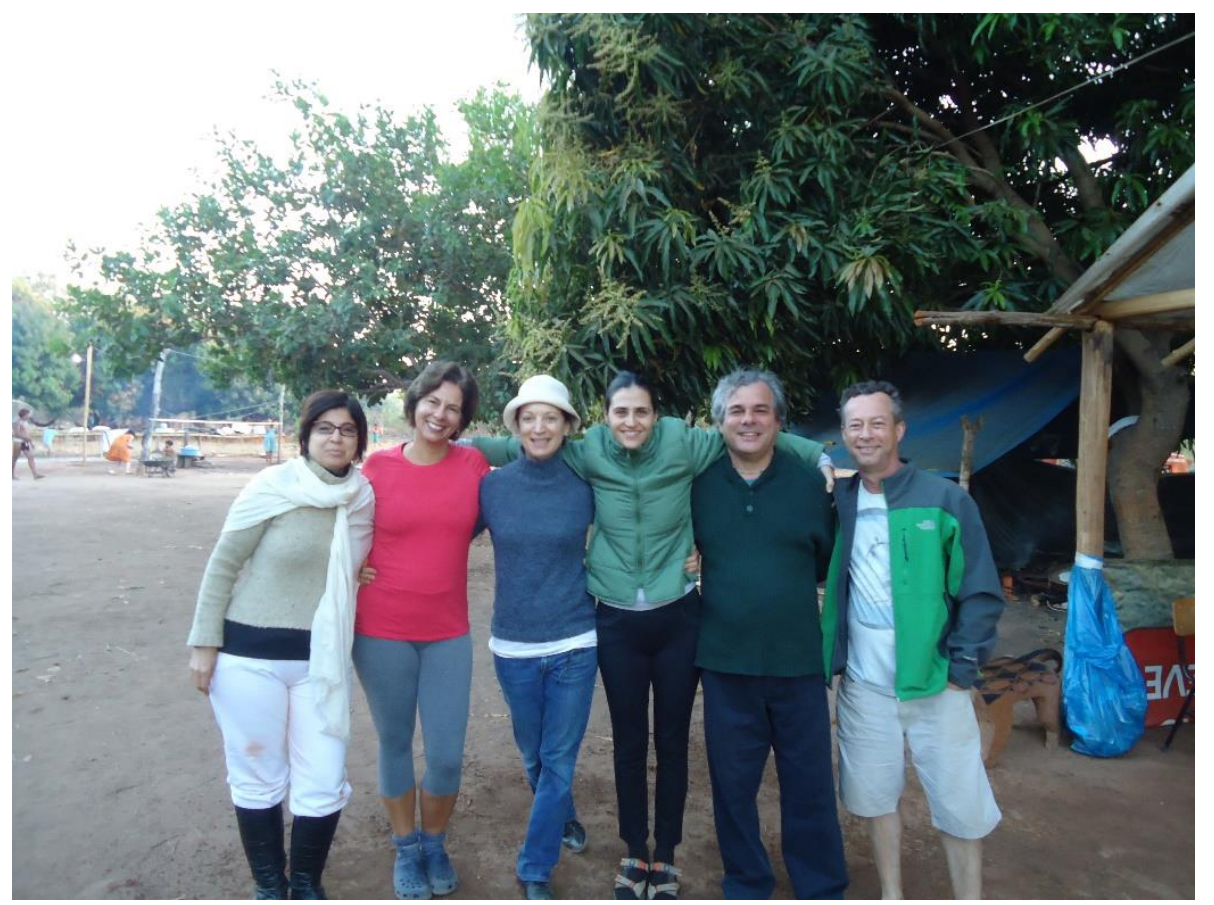

Fonte: Acervo pessoal- Ritual Kuarup - Parque indígena do Xingu, agosto de 2012. 


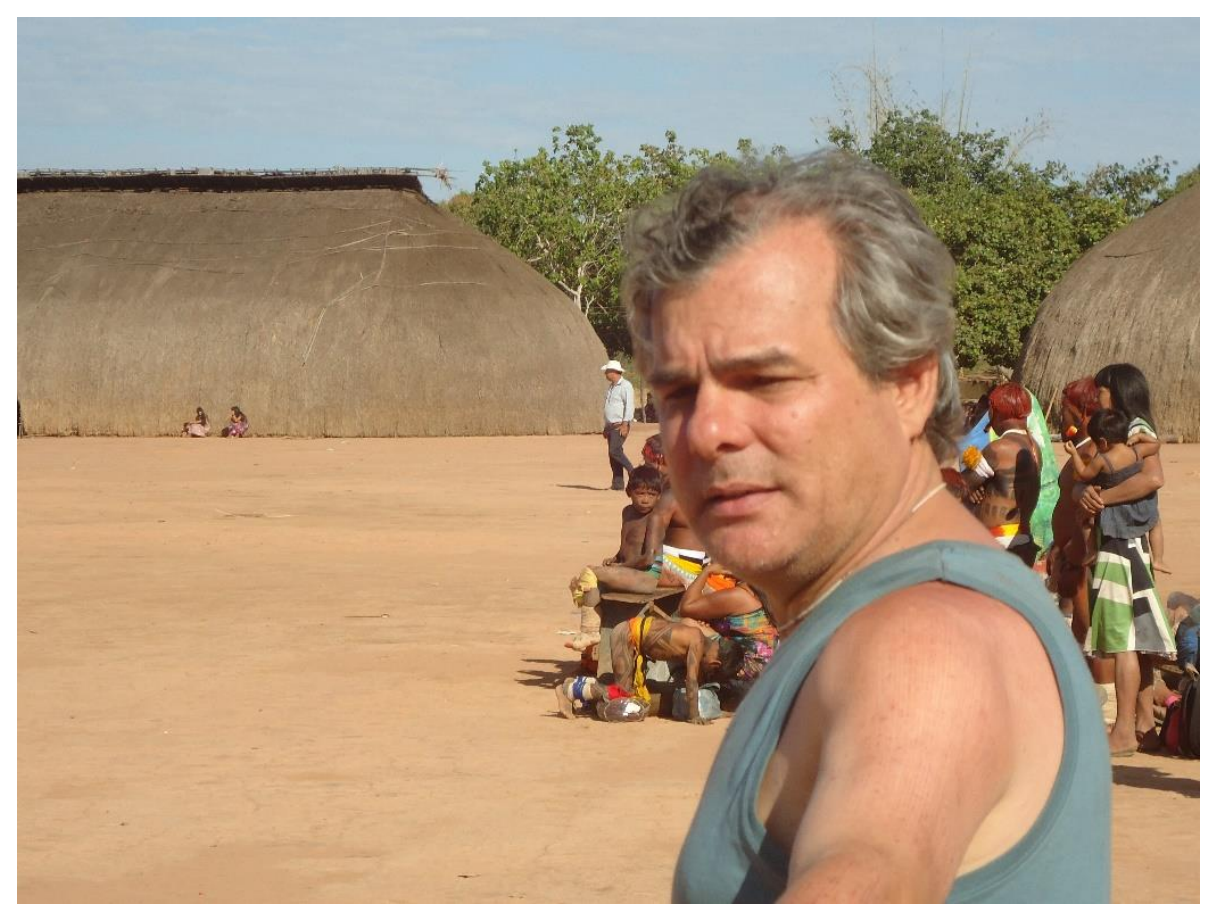

Fonte: Laura Virgínia Farias de Almeida Murta- Ritual Kuarup - Parque indígena do Xingu, agosto de 2012.

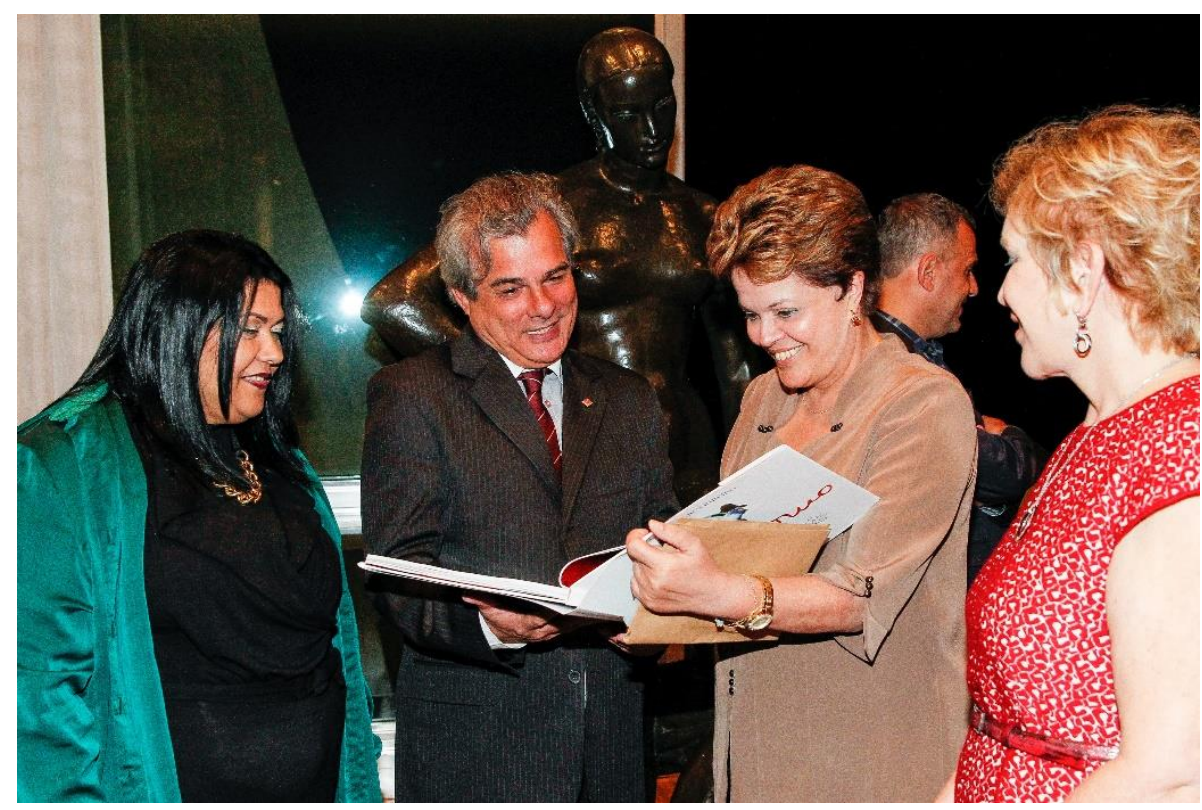

Fonte: Laura Virgínia Farias de Almeida Murta - Rio de Janeiro, 2014.

Artigo recebido em: 26 de agosto de 2021.

Artigo aceito em: 05 de setembro de 2021. Artigo publicado em: 13 de setembro de 2021. 